\title{
In Search of Product Uniqueness: Insight From Indonesia
}

\author{
Agung Wahyu Handaru ${ }^{1 *}$, Marsellisa Nindito ${ }^{1}$ \\ ${ }^{1}$ Universitas Negeri Jakarta \\ Email: agung_1178@yahoo.com
}

\begin{abstract}
This paper aimed to examine the factors which generate the uniqueness of products. This study developed 26 indicators of product uniqueness. Afterwards, the indicators were grouped using factor analysis. In this research, 250 respondents were participated, which according to KaiserMeyer-Olkin's measure of sampling adequacy, is suitable for research purpose. The factor analysis test eliminated 9 criterias of product uniqueness, which left 17 criterias that can be categorised into 4 groups using principal component analysis extraction method and varimax rotation. The first group category is 'basic value', which consists of 7 indicators. The second group category is differentiation, which has 3 indicators. The third category is technology, which comprises of 3 indicators. The fourth category is additional function, which consists of 4 indicators. The findings demonstrate that 'handmade' is the strongest indicator of product uniqueness. Based on the correlation test, there are 3 discoveries. First, product differentiation highly correlates with culture. Second, spectacular product correlates with bigger size. Third, luxury product correlates with bigger size. The research findings indicate that the manufacturer should start including cultural elements in regards of production or service, and concentrate on size for luxury products.
\end{abstract}

Type of Paper: Empirical

Keywords: Product Uniqueness; Product Differentiation; Product Innovation

\section{Introduction}

Studies on product uniqueness have become the primary interest of many strategic management and business strategy scholars for more than three decades. Lynn and Judy (1997) identify the antecedentsandconsequences of the desire of unique consumer product. Cavusgiland Zou (1994) and Jusoh and Parnel (2008) mention that the degree of product uniqueness highly correlates with the marketing performance. However, they did not mention specifically what aspect that generates product uniqueness. Some experts found that uniqueness can also be introduced in service areas (Dibb \& Simkin, 1993; Valikangas \& Lehtinen, 1994; Millar, Choi, \& Chen, 2005). However, most of them only explained general concept of service positioning strategy instead of service uniqueness aspect. Other scholars have observed the correlation between product uniqueness and manufacturing infrastructure. St John and Harrison (1999) explained that manufacturing infrastructure plays an important role to create product uniqueness. 
Similarly, Bloch (1995), Rao, McLaughlin and Hawkes (1995) state that manufacturing organization is crucial to develop new product uniqueness and increased positive consumer response. In addition, Salavou and Avlonitis (2008) found that product uniqueness is essential for small and medium enterprises. However, they fail to discover the specific aspects of product uniqueness.

According to a study of product uniqueness by Swink and Hegarty (1998) and Franke and Schreier (2008), uniqueness is a result of great reliability, durability, fitness, performance, and the extent of exclusiveness and rareness. Despite being able to discover the aforementioned factors of product uniqueness, this study fail to provide more detailed dimensions.

Early work of Karger (1966) found that product uniqueness is the outcome of a manufacturing innovation. Several scholars believe that manufacturing capabilities are vital to create uniqueness (Goldhar \& Lei, 1995; Swift \& Raines, 1999; Fynes, De Burca, Brannick, \& Glynn, 2000). Study of Cil and Ramazan (1998) highlighted the role of expert system manufacturing in product design. Noble $(1995,1997)$ found that manufacturing capabilities are crucial on promoting product innovation. Likewise, Narasimhan and Das (1999) assert that manufacturing flexibility is needed to develop a new product with high uniqueness.

Although product uniqueness has been widely discussed and examined, there was a knowledgegap regarding the factors associate with product uniqueness. Thus, it motivated this study to investigate product uniqueness aspects derived from consumer perspective. Knowing the perspective of consumers is essential since it will disclose what kind of features they need on a product.

Following this introductory section, this paper is structured as follows. First, literature review and conceptual framework are detailed. Second, the method used to manage empirical testing is explained. Third, the results are presented. This paper ends with the discussion of findings, conclusion, and advices of future research.

\section{Literature Review}

\section{Product Uniqueness}

Some scholars argued that people are unhappy if they use similar product like others (Fromkin, 1970; Snyder \& Fromkin, 1980). Furthermore, Lynn and Harris (1997) argue that each consumer has different desire for unique products. They believe that every consumer has a need for uniqueness and propensity to admire scarce product. In the words of Valikangas and Lehtinen (1994), uniqueness is the core of differentiation strategy. They assert that differentiation strategy should focus on adding value, such as uniqueness of products or services. According to Rao, McLaughlin and Hawkes (1995), uniqueness plays an important role when a company wants to launch a new product. Moreover, the popularity of a new product is determined by the extent of its uniqueness. Similarly, Bloch (1995) state that a unique product has more positive consumer response and easily acquire marketplace accomplishment.

\section{Product Differentiation}

According to Holcombe (2009), the aim of product differentiation is not merely to create 
a different product, but also to make a better product. Moreover, he states that product differentiation can be the engine of economic advancement. Hamilton and Richards (2009) and Chung, Lin and $\mathrm{Hu}$ (2013) found that the level of product differentiation positively affects its retail margin.

Chung, Lin, and $\mathrm{Hu}$ (2013) examined the relationship between product differentiation and bundling strategy. The findings show that product differentiation can increase consumer and social surplus. In a study of product differentiation, Davcik and Sharma (2015) discover that in Industrial Organization (IO) concept, product differentiation can help companies to avoid price war, which can jeopardize profit and market share. Moreover, the result suggests that product differentiation will build market niche and new marketplace.

\section{Product Innovation}

Lofsten (2014) explains that product innovation is very crucial in total product life-cycle administration. Additionally, he argues that naturally, product innovation is "highly uncertain" and requires high level of manufacturing capabilities. As claimed by Hoonsopon and Ruenrom (2012), product innovation can be viewed from technology and customers' perspectives. Later, they state that product innovation is better to be look at through consumers' perspectives. In addition, they argue that product innovation is a result of high level of manufacturing capability. While previously mentioned studies only focus on manufacturing capability, Henke and Zhang (2010) has introduced a different focus on product innovation. Based on the results, that suppliers are vital sources of product innovation. Similar findings were found by Azadegan, Dooley, Carter and Carter (2008). Griffin and Hauser (1996) and Carlsson (1991) have similar findings regarding the importance of product innovation on product performance.

\section{Conceptual Framework}

Defining the clear indicators of product uniqueness is difficult. This is mainly caused by many interpretation of tangible and intangible uniqueness aspects from customer's standpoint. Consistent opinion about the definition of product uniqueness is relatively erratic since technology and manufacturing capability can help the development of new product rapidly. However, there must be some reliable features that repeatedly occurred in what customer considers as a unique product. These reliable features are best retrieved from customer's perspective because they are the final user of the products. Another ambiguous element of product uniqueness is the extent of its indicators association. Ambiguity in the indicators of product uniqueness can create a misperception regarding what customers truly need. Hence, a clearer uniqueness indicators and association among them will help the manufacturer to develop new product with superior level of uniqueness.

\section{Research Methods}

This study administered simple mean rank and factor analysis to get specific groups of product uniqueness indicators. All data which collected from 250 respondents have undergone KaiserMeyer-Olkin measure of sampling adequacy to determine sampling acceptability. The total of initial eigenvalues is employed to see how many groups can be formed from 26 original indicators, gathered from early interview among 50 respondents of master degree students. Judgment sampling is applied in this research. 250 master degree students were selected 
Table 1. Sample Information

\begin{tabular}{llllll}
\hline No & Aspect & Score (n=250) & & & \\
\hline 1 & Gender & Male & Female & & \\
\hline & & $112 / 44.8 \%$ & $138 / 55.2 \%$ & & \\
\hline 2 & Age & $<20$ & $21-30$ & $31-40$ & \\
\hline & & $35 / 14 \%$ & $95 / 38 \%$ & $57 / 22.8 \%$ & $63 / 25.2 \%$ \\
\hline 3 & Monthly Income (USD) & $200-500$ & $501-800$ & $>800$ & Others \\
\hline & & $90 / 36 \%$ & $83 / 33.2 \%$ & $52 / 20.8 \%$ & $25 / 10 \%$ \\
\hline 4 & Career & Govn Officer & Employee & Student & Entrep \\
\hline & & $54 / 21.6 \%$ & $96 / 38.4 \%$ & $50 / 20 \%$ & $50 / 20 \%$ \\
\hline 5 & Education & Diploma & Bachelor & Master & Ph.D \\
\hline & & $41 / 16.4 \%$ & $148 / 59.2 \%$ & $45 / 18 \%$ & $16 / 6.4 \%$ \\
\hline
\end{tabular}

Table 2. Indicators of Unique Product/Service

\begin{tabular}{lll}
\hline Rank & Indicator & Mean \\
\hline 1 & Handmade & 4.8 \\
\hline 2 & Comfort & 4.7 \\
\hline 3 & Staff & 4.7 \\
\hline 4 & Culture & 4.6 \\
\hline 5 & Lux & 4.6 \\
\hline 6 & Diff & 4.5 \\
\hline 7 & Natural & 4.5 \\
\hline 8 & Spect & 4.5 \\
\hline 9 & Bigger & 4.5 \\
\hline 10 & Facilitate & 4.5 \\
\hline 12 & Dependable & 4.4 \\
\hline 13 & Spirit & 4.4 \\
\hline 14 & Rare & 4.3 \\
\hline 15 & Durable & 4.3 \\
\hline 16 & Techno & 4.1 \\
\hline 17 & Del & 4.1 \\
\hline
\end{tabular}

to participate in this survey. Rotated component matrix and varimax rotation is managed to determine the composition of indicator for each group. To examine the association of product uniqueness indicators, the Pearson Correlation Coefficient (PCC) test is utilized.

\section{Result}

General information of research samples is portrayed in table 1.

\section{Indicators of Unique Product}

This study used 26 indicators gathered from customer perspective of what they called unique product or service. Afterwards, all indicators were ranked based on respondent's response in term of uniqueness aspect. Minimum mean score of 4.0 was applied as cut-off point to select acceptable indicators that can truly reflect the uniqueness of a product. Justification of cut-off point is based on consideration that mean score of 4.0 relatively reflects high importance from respondent standpoint. The result of ranked indicators is shown table 2.

Table 2 shows that nine indicators were eliminated. The best three indicators of product uniqueness are handmade, comfort, and staff. In order to apply factor analysis for 17 indicators, the Kaiser-Meyer-Olkin measure of sampling adequacy was used to check sampling acceptability. 
Table 3. KMO and Bartlett's Test

\begin{tabular}{|c|c|c|}
\hline \multicolumn{2}{|c|}{ Kaiser-Meyer-Olkin Measure of Sampling Adequacy. } & .881 \\
\hline \multirow[t]{3}{*}{ Bartlett's Test of Sphericity } & Approx. Chi-Square & 1170.294 \\
\hline & $\mathrm{df}$ & 136 \\
\hline & Sig. & .000 \\
\hline
\end{tabular}

Table 4. Total Variance Explained

\begin{tabular}{|c|c|c|c|c|c|c|c|c|c|}
\hline \multirow[b]{2}{*}{ Comp } & \multicolumn{3}{|c|}{ Initial Eigenvalues } & \multicolumn{6}{|c|}{ Extraction Sums of Squared Loadings Rotation Sums of Squared Loadings } \\
\hline & Total & $\begin{array}{c}\% \text { of } \\
\text { Variance } \\
\end{array}$ & $\begin{array}{c}\text { Cumulative } \\
\% \\
\end{array}$ & Total & $\begin{array}{c}\% \text { of } \\
\text { Variance }\end{array}$ & $\begin{array}{c}\text { Cumulative } \\
\% \\
\end{array}$ & Total & $\begin{array}{c}\% \text { of } \\
\text { Variance }\end{array}$ & $\begin{array}{c}\text { Cumulative } \\
\% \\
\end{array}$ \\
\hline 1 & 5.511 & 32.416 & 32.416 & 5.511 & 32.416 & 32.416 & 2.642 & 15.541 & 15.541 \\
\hline 2 & 1.309 & 7.698 & 40.114 & 1.309 & 7.698 & 40.114 & 2.191 & 12.888 & 28.429 \\
\hline 3 & 1.143 & 6.726 & 46.840 & 1.143 & 6.726 & 46.840 & 2.169 & 12.757 & 41.186 \\
\hline 4 & 1.052 & 6.191 & 53.031 & 1.052 & 6.191 & 53.031 & 2.014 & 11.845 & 53.031 \\
\hline 5 & .966 & 5.680 & 58.712 & & & & & & \\
\hline 6 & .901 & 5.298 & 64.010 & & & & & & \\
\hline 7 & .774 & 4.552 & 68.561 & & & & & & \\
\hline 8 & .753 & 4.431 & 72.992 & & & & & & \\
\hline 9 & .692 & 4.072 & 77.064 & & & & & & \\
\hline 10 & .630 & 3.704 & 80.769 & & & & & & \\
\hline 11 & .587 & 3.451 & 84.220 & & & & & & \\
\hline 12 & .566 & 3.331 & 87.550 & & & & & & \\
\hline 13 & .512 & 3.011 & 90.562 & & & & & & \\
\hline 14 & .480 & 2.824 & 93.386 & & & & & & \\
\hline 15 & .433 & 2.545 & 95.931 & & & & & & \\
\hline 16 & .381 & 2.244 & 98.175 & & & & & & \\
\hline 17 & .310 & 1.825 & 100.000 & & & & & & \\
\hline
\end{tabular}

Extraction Method: Principal Component Analysis.

As the score of KMO in table 3 is 0.881 , it is confirmed that the sampling adequacy is acceptable. Hence, the data in this study can be used for further analysis. To discover how many groups can be formed from 17 indicators, the total of initial eigenvalues is used as screening indicator.

Table 4 shows that optimum group that can be formed from 17 criteria is four with cumulative of $53.031 \%$. Four components of indicator are the optimum result because total initial eigenvalues for more than four groups is below 1.00. To get the best composition of all indicators for each component, the present study used rotated component matrix score.

Table 5 shows the final iteration for varimax rotation method. It is revealed that component one comprises seven indicators, which are comfort, facility, staff, bigger, luxury, dependable, and rare. Component two has three indicators such as handmade, differentiation, and culture. Component three comprises of three indicators which are spiritual, technology, and durable. Component four has four indicators which are delicious, beautiful, natural, and spectacular. After that, they were named as "basic value"; "differentiation"; "technology"; and "additional function". 
Table 5. Rotated component matrixa

\begin{tabular}{|c|c|c|c|c|}
\hline & \multicolumn{4}{|c|}{ Component } \\
\hline & 1 & 2 & 3 & 4 \\
\hline Hand & .438 & .563 & -.031 & .105 \\
\hline$\underline{\text { Diff }}$ & -.046 & .709 & .323 & .026 \\
\hline Culture & .179 & .821 & .112 & .118 \\
\hline Delic & .375 & .039 & -.113 & .564 \\
\hline Beauty & .035 & -.020 & .117 & .798 \\
\hline Spirit & .200 & .161 & .616 & .077 \\
\hline Comf & .591 & .143 & .465 & .130 \\
\hline Facil & .726 & -.119 & .139 & .049 \\
\hline$\underline{\text { Staff }}$ & .465 & .309 & .220 & .190 \\
\hline Nat & .116 & .429 & .268 & .548 \\
\hline Spect & .177 & .259 & .246 & .547 \\
\hline$\underline{B i g}$ & .458 & .359 & .277 & .373 \\
\hline Tech & .017 & .066 & .730 & .116 \\
\hline Dur & .270 & .188 & .690 & .127 \\
\hline$\underline{\text { Lux }}$ & .668 & .240 & .163 & .174 \\
\hline Dep & .434 & .010 & .338 & .393 \\
\hline Rare & .423 & .253 & .027 & .135 \\
\hline
\end{tabular}

A. Rotation converged in 7 iterations.

Table 6. Correlation of Indicators

\begin{tabular}{|c|c|c|c|c|c|c|c|c|c|c|c|c|c|c|c|c|c|}
\hline & Hand & Diff & $\mathrm{Cul}$ & Del & Beauty & Spirit & Comf & $\mathrm{Fac}$ & Staff & Nat & Spect & Big & Tech & Dur & Lux & Dep & rare \\
\hline Hand & 1.00 & & & & & & & & & & & & & & & & \\
\hline Diff & 0.21 & 1.00 & & & & & & & & & & & & & & & \\
\hline $\mathrm{Cul}$ & 0.45 & 0.53 & 1.00 & & & & & & & & & & & & & & \\
\hline Del & 0.24 & 0.11 & 0.17 & 1.00 & & & & & & & & & & & & & \\
\hline Beauty & 0.16 & 0.07 & 0.16 & 0.29 & 1.00 & & & & & & & & & & & & \\
\hline Spirit & 0.23 & 0.22 & 0.24 & 0.11 & 0.20 & 1.00 & & & & & & & & & & & \\
\hline Comf & 0.31 & 0.25 & 0.30 & 0.22 & 0.22 & 0.39 & 1.00 & & & & & & & & & & \\
\hline Fac & 0.17 & 0.10 & 0.13 & 0.26 & 0.14 & 0.17 & 0.40 & 1.00 & & & & & & & & & \\
\hline Staff & 0.36 & 0.24 & 0.33 & 0.24 & 0.26 & 0.27 & 0.40 & 0.27 & 1.00 & & & & & & & & \\
\hline Nat & 0.29 & 0.34 & 0.40 & 0.24 & 0.35 & 0.27 & 0.36 & 0.16 & 0.34 & 1.00 & & & & & & & \\
\hline Spect & 0.21 & 0.22 & 0.30 & 0.23 & 0.27 & 0.26 & 0.32 & 0.22 & 0.21 & 0.43 & 1.00 & & & & & & \\
\hline Big & 0.41 & 0.30 & 0.38 & 0.31 & 0.25 & 0.33 & 0.46 & 0.29 & 0.36 & 0.39 & 0.56 & 1.00 & & & & & \\
\hline Tech & 0.18 & 0.21 & 0.17 & 0.08 & 0.15 & 0.26 & 0.33 & 0.08 & 0.22 & 0.22 & 0.24 & 0.26 & 1.00 & & & & \\
\hline Dur & 0.22 & 0.32 & 0.31 & 0.20 & 0.18 & 0.42 & 0.40 & 0.28 & 0.35 & 0.38 & 0.26 & 0.42 & 0.39 & 1.00 & & & \\
\hline Lux & 0.36 & 0.17 & 0.37 & 0.26 & 0.19 & 0.26 & 0.47 & 0.38 & 0.30 & 0.37 & 0.34 & 0.49 & 0.18 & 0.36 & 1.00 & & \\
\hline Dep & 0.23 & 0.18 & 0.23 & 0.29 & 0.29 & 0.22 & 0.40 & 0.30 & 0.35 & 0.33 & 0.29 & 0.38 & 0.27 & 0.36 & 0.40 & 1.00 & \\
\hline rare & 0.25 & 0.10 & 0.20 & 0.15 & 0.14 & 0.19 & 0.29 & 0.12 & 0.33 & 0.25 & 0.23 & 0.31 & 0.15 & 0.16 & 0.29 & 0.19 & 1.00 \\
\hline
\end{tabular}

Correlation among seventeen indicators was confirmed by Pearson Correlation test as depicted in table 6. Result in table 6 showed that there are two strong correlations among indicators represented by above 0.5 correlation score. First, there is a strong correlation between product differentiation and culture $(0.53)$. This finding confirmed that from customer standpoint, unique product is a product that 
inserts traditional or cultural aspect whether in its design, process, delivery, or how the product is promoted. These kinds of products include "keris" (traditional knife blade form many regions in Indonesia), "batik tulis" (traditional fabric and clothes) or craftsmanship products such as sculpture, painting, and handmade furniture. Second, there is a strong correlation between bigger size and spectacular perception (0.56). This finding confirmed that from customer view, something is called spectacular when it has bigger size than average. Real application can be found in some products like cars (limousine), animals (dinosaurs), or even tourist destination (Mount Bromo). Complete correlation scores for all indicators are shown in table 6.

\section{Discussion}

Customer claimed that unique product is frequently built by handmade. Naturally, product which built by handmade has something special that machines could not do. Handmade products tend to have more details and personal touch. Pattern, design, and shape which are created by human hand have discontinuous sequence that can promotes the one and only product. Handmade products are difficult to copy because it was built with tacit knowledge. On the other hand, products that insert cultural or traditional elements would probably have more opportunity to become unique. The cause of this phenomenon may be the difficulty of re-creating the cultural and traditional elements.

Some customers also assumed that something luxurious tend to have the size bigger than average. Cases are including cars, motorcycle, houses, and jewelry. In contrast, previous studies, the result shows that customers do not view product uniqueness as result of manufacturing capability. This might be caused by general condition of Indonesia manufacturing which is relatively less competitive in the global industry. This lowers customer trust on machinery and manufacturing process.

Beside of built by handmade, customers are generally believed that unique product should distinctively different in its tangible design, offers high level of comfort, or looks very expensive (with application of premium or rare materials). Meanwhile, in service business like hotels, uniqueness appears from staffs who served guests. Staff uniqueness associates with high level of politeness, courteousness, and spirit of helpfulness. Another indicator for service uniqueness is the extent of spiritual ambience especially in tourism sector. The best example of the spiritual ambience practice is Bali.

\section{Conclusion}

This study explored robust indicators of product uniqueness from customer's standpoint, which are needed to help manufacturer reformulates his/her business strategy and to achieve business sustainability. Some steps were used to answer the research questions. First, mean rank score was used to select the best uniqueness indicators. Then, factor analysis technique was used to determine how many groups of components can be formed from the selected indicators. In the final step, this study employed Pearson Correlation Coefficient test to discover the relationship that occurs among selected indicators.

There are three important findings of this study. First, the best indicator of product uniqueness is handmade. Second, product uniqueness can be categorized into four dimensions. Third, 
there are strong relationship between product differentiation and culture, in addition to bigger size and spectacular perception. Future research is needed to see the consistency of present indicators with additional aspects such as brand reputation, and country maker image.

\section{Limitation of the Study}

This paper has two limitations. First, the uniqueness criteria for goods and services is not specifically differentiated. Second, the samples are limited only for master degree students and therefore, further research should be applied in more varied consumers.

\section{References}

Azadegan, A., Dooley, K.J., Carter, P.L., Carter, J.R. (2008), Supplier Innovativeness and the Role of Interorganizational Learning in Enhancing Manufacturer Capabilities. Journal of Supply Chain Management, 44(4), 14-35

Bloch, P. H. (1995). Seeking the Ideal Form: Product Design and Consumer Response. Journal of Marketing, 59(3), 16

Carlsson, M. (1991), Aspects of the Integration of the Technical Function for Efficient Product Development. R\&D Management, 20(1), 55-66

Cil, I., Evren, R. (1998). Linking of Manufacturing Strategy, Market Requirements and Manufacturing Attributes in Technology Choice: An Expert System Approach. The Engineering Economist, 43(3), 183

Chung, H.L., Lin, Y.S, Hu, J.L. (2013). Bundling Strategy and Product Differentiation. Journal of Economics, 108, 207-229

Davcik, N.S., Sharma, P. (2015). Impact Of Product Differentiation, Marketing Investments And Brand Equity On Pricing Strategies: A Brand Level Investigation. European Journal of Marketing, 49(5/6), 760-781

Dibb, S., Simkin. (1993). The Strength Of Branding And Positioning In Services. International Journal of Service Industry Management, 4(1), 25

Franke, N., Schreier, M. (2008). Product Uniqueness as a Driver of Customer Utility in Mass Customization. Marketing Letter, 19, 93-107.

Fromkin, H. L. (1970). Effect of Experimentally Aroused Feelings of Indistinctiveness upon Valuation of Scarce and Novel Experiences. Journal of Personality and Social Psychology, 16, 521-529

Fynes, B., de Burca, S., Brannick, T., Glynn, W. (2000). Quality Practices, Quality Performance And Business Performance: A Test of Trade off and Multiple Capabilities Theories. IBAR, 21(1), 29 
Griffin, A., Hauser, J.R. (1996), Integrating R\&D and Marketing: A Review and Analysis of Literature. Journal of Product Innovation Management, 13,191-215.

Goldhar, J. D., Lei, D. (1995). Variety is Free: Manufacturing In the Twenty-First Century. The Academy of Management Executive, 9(4), 73

Hamilton, S. F., Richards, T. J. (2009). Product Differentiation, Store Differentiation, and Assortment Depth. Management Science, 55(8), 1368-1376

Henke, J.W. Jr., Zhang, C. (2010), Increasing Supplier-Driven Innovation. MIT Sloan Management Review, 51(2), 41-46.

Hoonsopon, D., Ruenrom, G. (2012). The Impact of Organizational Capabilities on the Development of Radical and Incremental Product Innovation and Product Innovation Performance. Journal of Managerial Issues, 24(3), 250-276

Holcombe, R. G. (2009). Product Differentiation and Economic Progress. The Quarterly Journal of Austrian Economics, 12(1), 17-35

Hsu, Y. (2011). Design Innovation and Marketing Strategy in Successful Product Competition. Journal of Business \& Industrial Marketing, 26(4), 223-236

Jusoh, R., Parnel, J. A. (2008). Competitive Strategy and Performance Measurement in the Malaysian Context an Exploratory Study. Management Decision, 46(1), 5-31

Karger, D W. (1966). Product Design, Marketing, and Manufacturing Innovation. California Management Review, 9 (000002), 33

Lofsten, H. (2014). Product Innovation Processes and the Trade-Off between Product Innovation Performance and Business Performance. European Journal of Innovation Management. 17(1), 61-84

Lynn, M., Harris, J. (1997). The Desire for Unique Consumer Products: A New Individual Differences Scale. Psychology \& Marketing, 14 (6), 601

Millar, C., Choi, C., Chen, S. (2005). Globalization Rediscovered: The Case of Uniqueness and "Creative Industries". Management International Review, 45(1), 121

Narasimhan, R., Das, A. (1999). An Empirical Investigation of the Contribution of Strategic Sourcing to Manufacturing Flexibilities and Performance. Decision Sciences; 30(3), 683

Noble, M.A. (1997). Manufacturing Competitive Priorities and Productivity: An Empirical Study. International Journal of Operations \& Production Management, 17(1), 85-99.

Noble, M.A. (1995). Manufacturing Strategy: Testing the Cumulative Model in a Multiple Country Context. Decision Sciences, 26(5), 693. 
Rao, V. R., McLaughlin, E.W., Hawkes, G.F. (1995). Supermarket Buyer Evaluations of Hypothetical New Products: An Empirical Analysis. Agribusiness, 11(1), 2

Salavou, H., Avlonitis, G. (2008). Product Innovativeness and Performance: A Focus on SMEs. Management Decision, 46(7), 969-985

Snyder, C. R., Fromkin, H. L. (1980). Uniqueness: The Human Pursuit of Difference. New York: Plenum Press.

St.John, C.H., Harrison, J. (1999). Manufacturing-Based Relatedness, Synergy, and Coordination. Strategic Management Journal, 20(2), 129.

Swift, K G., Raines, M., Booker, J D. (1999). Analysis of Product Capability at the Design Stage. Journal of Engineering Design, 10(1), 77

Swink, M., Hegarty, W.H. (1998). Core Manufacturing Capabilities and Their Links to Product Differentiation. International Journal of Operations \& Production Management, 4, 374-396,

Tamer, C.S., Zou, S. (1994). Marketing Strategy-Performance Relationship: An Investigation. Journal of Marketing, 58(1), 1

Valikangas, L., Lehtinen, U. (1994). Strategic Types of Services and International Marketing. International Journal of Service Industry Management, 5(2), 72 